\title{
Novel formulation of a methotrexate derivative with a lipid nanoemulsion
}

This article was published in the following Dove Press journal:

International Journal of Nanomedicine

I| October 20 | |

Number of times this article has been viewed

Juliana A Moura'

Claudete J Valduga ${ }^{2}$

Elaine R Tavares'

lara F Kretzer ${ }^{1,4}$

Durvanei A Maria ${ }^{3}$

Raul C Maranhão1,4

'Heart Institute of the Medical School Hospital, University of São Paulo; ${ }^{2}$ Bandeirante University of São Paulo; ${ }^{3}$ Butantan Institute,

${ }^{4}$ Faculty of Pharmaceutical

Sciences of the University

of São Paulo, São Paulo, Brazil
Correspondence: Raul C Maranhão Lipid Metabolism Laboratory, Heart Institute, Medical School Hospital, University of São Paulo, São Paulo, SP, Brazil

Tel +55 II 3069595 I

Fax +55 II3 0695574

Email ramarans@usp.br
Background: Lipid nanoemulsions that bind to low-density lipoprotein receptors can concentrate chemotherapeutic agents in tissues with low-density lipoprotein receptor overexpression and decrease the toxicity of the treatment. The aim of this study was to develop a new formulation using a lipophilic derivative of methotrexate, ie, didodecyl methotrexate (ddMTX), associated with a lipid nanoemulsion (ddMTX-LDE).

Methods: ddMTX was synthesized by an esterification reaction between methotrexate and dodecyl bromide. The lipid nanoemulsion was prepared by four hours of ultrasonication of a mixture of phosphatidylcholine, triolein, and cholesteryloleate. Association of ddMTX with the lipid nanoemulsion was performed by additional cosonication of ddMTX with the previously prepared lipid nanoemulsion. Formulation stability was evaluated, and cell uptake, cytotoxicity, and acute animal toxicity studies were performed.

Results: The yield of ddMTX incorporation was $98 \%$ and the particle size of LDE-ddMTX was $60 \mathrm{~nm}$. After 48 hours of incubation with plasma, approximately $28 \%$ ddMTX was released from the lipid nanoemulsion. The formulation remained stable for at least 45 days at $4{ }^{\circ} \mathrm{C}$. Cytotoxicity of LDE-ddMTX against K562 and HL60 neoplastic cells was higher than for methotrexate (50\% inhibitory concentration $\left[\mathrm{IC}_{50}\right] 1.6$ versus $18.2 \mathrm{mM}$ and 0.2 versus $26 \mathrm{mM}$, respectively), and cellular uptake of LDE-ddMTX was 90-fold higher than that of methotrexate in K562 cells and 75-fold in HL60 cells. Toxicity of LDE-ddMTX, administered at escalating doses, was higher than for methotrexate $\left(\mathrm{LD}_{50} 115 \mathrm{mg} / \mathrm{kg}\right.$ versus $470 \mathrm{mg} / \mathrm{kg}$; maximum tolerated dose $47 \mathrm{mg} / \mathrm{kg}$ versus $94 \mathrm{mg} / \mathrm{kg}$ ) in mice. However, the hematological toxicity of LDE-ddMTX was lower than for methotrexate.

Conclusion: LDE-ddMTX was stable, and uptake of the formulation by neoplastic cells was remarkably greater than of methotrexate, which resulted in markedly greater cytotoxicity. LDE-ddMTX is thus a promising formulation to be tested in future animal models of cancer or rheumatic disease, wherein methotrexate is widely used.

Keywords: nanoparticles, methotrexate, didodecyl methotrexate, drug delivery, cholesterol

\section{Introduction}

Methotrexate (2,4-diamino, $N^{10}$-methylpteroyl glutamic acid) is an antiproliferative and immunosuppressive agent widely used against a broad spectrum of diseases. Methotrexate is a potent inhibitor of dihydrofolate reductase, and can also inhibit thymidylate synthase and 5-aminoimidazole carboxamide ribotide transformylase. These enzymes are involved in the synthesis of thymidylate, purines, methionine, and serine. ${ }^{1}$ Methotrexate was introduced in the 1940 s, and is still used extensively in clinical practice. Methotrexate has relatively low toxicity compared with other chemotherapeutic agents, ${ }^{2}$ but is not devoid of side effects, including nephrotoxicity, 
hepatotoxicity, myelotoxicity, interstitial pneumonitis, and chronic interstitial obstructive pulmonary disease. ${ }^{3}$

The effectiveness of methotrexate is often hampered by development of drug resistance mechanisms, such as inhibition of active transport involving the cell folate receptor that mostly internalizes methotrexate, and is hydrophilic and poorly diffused through cell membranes. Aiming to bypass drug resistance and yet retain cytotoxic activity, several strategies have been attempted. One of these strategies consists of chemical modification of methotrexate to improve lipophilicity. In this regard, the $\gamma$-carbonyl position is preferentially targeted to attach lipophilic groups to the methotrexate molecule, and in fact modification at the $\gamma$ and, to a lesser extent, the $\alpha$-carbonyl position did not decrease the drug cytotoxicity. ${ }^{4}$ Drug delivery systems have also been used to improve cytotoxicity and reduce toxicity, such as loading of methotrexate into liposomes, ${ }^{4,5}$ dendrimers, ${ }^{6}$ micelles, ${ }^{7}$ chitosan polymers, ${ }^{8}$ and tuftsin-like peptide carriers, ${ }^{9}$ as well as attachment to polymeric chains. Other formulations have been described, such as chylomicronlike emulsions, for oral use. ${ }^{10}$ The use of a solid lipid nanoparticle system as a methotrexate carrier was reportedly shown to improve drug pharmacokinetics and to achieve regression of Ehrlich ascites carcinoma in mice. ${ }^{11,12}$

The demonstration by Ho et $\mathrm{al}^{13}$ that low-density lipoprotein receptors are overexpressed in neoplastic cells, paved the way for the use of lipoproteins ${ }^{14-17}$ and subsequently of lipoprotein-like nanoemulsions ${ }^{18,19}$ as vehicles to concentrate chemotherapeutic agents in neoplastic tissues. Taking this approach, the low-density lipoprotein receptor-mediated endocytic pathway is used to internalize drug-loaded lipid particles. ${ }^{14-17}$ We showed that cholesterol-rich nanoemulsions, with a lipid structure mimicking low-density lipoprotein, has the ability to bind to low-density lipoprotein receptors. A lipid nanoemulsion is made without protein but, in contact with plasma, acquires apolipoprotein $\mathrm{E}$, which is recognized by low-density lipoprotein receptors. ${ }^{19,20}$ In preclinical studies using chemotherapeutic agents, such as carmustine ${ }^{21}$ and lipophilic derivatives of paclitaxel ${ }^{22}$ and etoposide,,$^{23,24}$ the toxicity of these agents was markedly reduced by association with a lipid nanoemulsion, while the pharmacological action was maintained or even increased. In clinical studies enrolling patients with breast and ovary cancer, the amount of lipid nanoemulsion accumulated in tumor tissue was markedly greater than in normal tissue..$^{25-28}$ In clinical trials enrolling patients with advanced solid tumors and hematological neoplasias, ${ }^{21,29}$ we showed that the toxicity of highdose preparations of carmustine, paclitaxel, and etoposide associated with a lipid nanoemulsion was minimal.
This study aimed to investigate whether the association of methotrexate and a lipid nanoemulsion could increase neoplastic cell uptake and cytotoxicity, and decrease the toxicity of the drug. To improve the association yield and stability of the formulation, two dodecyl groups were attached to the methotrexate molecule.

\section{Methods \\ Materials}

Methotrexate (Miantrex ${ }^{\circledR}$ ) was purchased from Pfizer (Bentley, Australia); triolein, cholesteryloleate, cholesterol, phosphatidylcholine, dimethyl sulfoxide, and cesium carbonate from Sigma (St Louis, MO); methanol and acetonitrile from Merck (Darmstadt, Germany); and methotrexate sodium salt from Deg Importacao De Produtos Quimicos Ltd (São Paulo, Brazil).

Nuclear magnetic resonance (NMR) of ${ }^{1} \mathrm{H}$ and ${ }^{13} \mathrm{C}$ used to characterize the ddMTX structure was performed using a Bruker DPX-300 instrument (Brucker, Karlsruhe, Germany). Purity was analyzed by high-performance liquid chromatography in a Shimadzu SPD-10 AV column (Shimadzu, Columbia, $\mathrm{ML}$ ). The structure of the ddMTX was also confirmed by mass spectrometry using a Q-TOF Ultima (Micromass, Manchester, UK) and elemental analysis using a Perkin Elmer CHN 2400 elemental analyzer (Perkin Elmer, Sciex, Shelton, CT). Transmission electron microscopy imaging of LDEMTX was performed using a LEO 906E transmission electron microscope (Zeiss, Oberkochen, Germany) at $100 \mathrm{kV}$.

Isogenic female BALB/c mice ( $\pm 20 \mathrm{~g}$, aged 30-45 days) were supplied by the Butantan Institute (São Paulo, Brazil). All animals used in this study were housed in a temperaturecontrolled room, with a 12-hour light/dark cycle, and food and water available ad libitum. The ethics committee of University of Sao Paulo Medical School Hospital approved all the animal experiments.

\section{Synthesis of ddMTX}

Briefly, ddMTX was synthesized following the method described by Rosowsky et al. ${ }^{30}$ Methotrexate sodium salt $(2.0 \mathrm{~g}, 4.1 \mathrm{mmol})$ was diluted in $120 \mathrm{~mL}$ of dimethylsulfoxide, and over it were added cesium carbonate (1.43 g, $4.40 \mathrm{mmol})$ and dodecyl bromide $(2.5 \mathrm{~g}, 10 \mathrm{mmol})$. The mixture was stirred for 24 hours at room temperature, and $100 \mathrm{~mL}$ of water was added to quench the reaction. The product was extracted with chloroform $(5 \times 50 \mathrm{~mL})$. The organic phase was washed with a saturated sodium chloride solution $(3 \times 100 \mathrm{~mL})$, dried with magnesium sulfate, filtered, and concentrated. The product was purified by liquid chromatography using silica gel (230-400 mesh) with 
methanol/chloroform, from $2.5 \%$ to $100 \%$ of methanol. Pf $122^{\circ} \mathrm{C}-124^{\circ} \mathrm{C}$. Yield was $98 \%$.

${ }^{1} \mathrm{H} \delta(\mathrm{ppm}): 0,86(6 \mathrm{H}, \mathrm{t}, J=6.0 \mathrm{~Hz}), 1.23(36 \mathrm{H}, \mathrm{s})$; 1.50-1.68 (4H, m), 2.08-2.20 (1H, m), 2.21-2.32 (2H, m), 2.42-2.50 (1H, m), $3.12(3 \mathrm{H}, \mathrm{s}), 4.00(2 \mathrm{H}, \mathrm{t}, J=6.0 \mathrm{~Hz}), 4.13$ $(2 \mathrm{H}, \mathrm{t}, J=6.0 \mathrm{~Hz}), 4.67(2 \mathrm{H}, \mathrm{s}), 4.75-4.83(1 \mathrm{H}, \mathrm{m}), 5.98$ $(2 \mathrm{H}, \mathrm{bs}), 6.69(2 \mathrm{H}, \mathrm{d}, J=6.0 \mathrm{~Hz}) ; 7,02(1 \mathrm{H}, \mathrm{bs}), 7.69(1 \mathrm{H}, \mathrm{d}$, $J=6.0 \mathrm{~Hz}), 8.56(1 \mathrm{H}, \mathrm{s}) .{ }^{13} \mathrm{C} \delta$ (ppm): 13.99, 22.54, 25.75, 27.31, 28.42, 29.15, 29.24, 29.53, 30.55, 31.80, 38.90, 52.16, $55.68,64.85,65.66,111.21,121.37,121.87,128.79,146.65$, $146.71,149.10,151.31,154.86,162.51,162.89,166.96$, 172.63, 173.21. Mass: 338.31, 381.27, 675.63, 791.48 (100), 792.49, 793.52. IV v $\left(\mathrm{cm}^{-1}\right): 3478.8,2924.2,2855.9,1737.5$, 1630.7, 1512.6, 1445.9, 1204.3, 1096.0, 816.9. Elemental analysis: Calc: $66.80(\mathrm{C}), 8.92(\mathrm{H}), 14.16(\mathrm{~N})$. Expt: 66.50 (C), $8.68(\mathrm{H}), 14.10(\mathrm{~N})$.

\section{High-pressure liquid chromatography measurements}

A high-pressure liquid chromatographic column equipped with an ultraviolet detector at $300 \mathrm{~nm}$ was used to analyze and quantify methotrexate and ddMTX. Chromatographic separation was achieved with a ShimPack $C_{18}$ (2) $5 \mu \mathrm{m}$ $(15 \mathrm{~cm} \times 6 \mathrm{~mm})$ analytical column (Phenomenex, Torrance, $\mathrm{CA}$ ) protected by a Luna $\mathrm{C}_{18}(2)$ guard cartridge. The mobile phase was methanol at a flow rate of $1.0 \mathrm{~mL} / \mathrm{minute}$ for ddMTX and buffer of sodium acetate:acetonitrile (90:10) for methotrexate. For quantification of both compounds, a calibration curve was constructed at concentration ranging from $78.12 \mathrm{ng}$ to $50,000 \mathrm{ng}$.

\section{Distribution coefficient}

The distribution coefficient is the log distribution coefficient at a particular $\mathrm{pH}$. Log D at pH 7.4 is often quoted to give an indication of the lipophilicity of a drug at the $\mathrm{pH}$ of blood plasma. In aqueous/organic systems, the organic phase concentration is, by convention, the numerator, and the aqueous phase concentration is the denominator. $1.0 \mathrm{~mL}$ of $n$-octanol and $1.0 \mathrm{~mL}$ of sodium phosphate buffer, $\mathrm{pH} 7.4$ were added to $1 \mathrm{mg}$ of ddMTX. The mixture was gently shaken for 24 hours at $37^{\circ} \mathrm{C}$. The amount of drug in each phase was quantified by high-pressure liquid chromatography.

\section{Preparation of lipid nanoemulsion and LDE-ddMTX}

In brief, the lipid nanoemulsion was prepared from a lipid mixture composed of $40 \mathrm{mg}$ cholesteryloleate, $20 \mathrm{mg}$ egg phosphatidylcholine, $1 \mathrm{mg}$ triolein, and $0.5 \mathrm{mg}$ cholesterol.
Emulsification of lipids by prolonged ultrasonic irradiation in aqueous media and the procedure of two-step ultracentrifugation of the crude emulsion with density adjustment by addition of $\mathrm{KBr}$ to obtain a lipid nanoemulsion were carried out as described previously. ${ }^{20}$ The lipid nanoemulsion was dialyzed against Tris solution ( $\mathrm{pH} 8.05$ ) and passed through a $0.22 \mu \mathrm{m}$ filter for the experiments.

ddMTX $6 \mathrm{mg}$ was incorporated into the lipid nanoemulsion ( $1 \mathrm{~mL}, 30 \mathrm{mg}$ of total lipids) by solubilization of ddMTX in ethanol (10\% v:v) and adding it into the emulsion. The solution was then sonicated for one hour at $70^{\circ} \mathrm{C}$ using a Branson Sonifier 450 (Danbury, CT), equipped with a $1 \mathrm{~cm}$ flat titanium probe. LDE-ddMTX was centrifuged at $3500 \mathrm{rpm}$ for 15 minutes to separate the LDE-ddMTX from the free form of the drug that precipitated to the bottom of the tube. LDE-ddMTX was then passed through a $0.22 \mu \mathrm{m}$ pore polycarbonate filter and kept at $4^{\circ} \mathrm{C}$ until it was used. The yield of each batch was assayed before use. For quantification of ddMTX-loaded LDE, $10 \mu \mathrm{L}$ LDE-ddMTX were dissolved in $1.0 \mathrm{~mL}$ of methanol to break the formulation. The ddMTX mass contained in the lipid nanoemulsion was measured in $20 \mu \mathrm{L}$ of the previous solution using a calibration curve. The amount of drug associated to the lipid nanoemulsion was always measured by high-performance liquid chromatography before the experiments.

\section{LDE-ddMTX particle size}

The average size of the LDE-ddMTX particles was measured using a zeta potential analyzer (Brookhaven Instruments Corporation, Holtsville, NY) at $25^{\circ} \mathrm{C}$. All the samples were kept at $4^{\circ} \mathrm{C}$ and diluted and filtrated immediately prior to diameter measurement. In order to evaluate the stability of the formulation, the mean diameters of the lipid nanoemulsion and LDE-ddMTX particles were measured over 45 days.

\section{Transmission electron microscopy of LDE-ddMTX}

Five microliters of LDE-ddMTX at approximately $0.2 \mathrm{mg} / \mathrm{mL}$ were applied on parlodium-carbon-coated copper grids of 300 or 400 meshes. After 1-2 minutes, the excess liquid is blotted with tissue paper, leaving a small amount of residual fluid. Negative staining was done with a $5 \mu \mathrm{L}$ drop of $2 \%$ ammonium molybdate $\mathrm{pH} 7.2$ for $5-10$ seconds and then blotted dry. Grids were examined under a LEO 906E transmission electron microscope (Zeiss, Oberkochen, Germany) at $100 \mathrm{kV}$ acceleration voltage. Images were acquired by a charge-coupled device camera (MegaView III) through the universal transmission electron microscope imaging platform program 
(Olympus Soft Imaging Solutions GMBh, Oberkochen, Germany), and saved in TIF extension.

\section{In vitro release of ddMTX from lipid nanoemulsion}

LDE-ddMTX was dialyzed against human plasma to evaluate drug release from the lipid nanoemulsion. The dialysis bags (Seamless cellulose tubing, Sigma) were soaked in deionized water before placing $1.0 \mathrm{~mL}$ of LDE-ddMTX into the bag. The bags were placed into a tube containing $20 \mathrm{~mL}$ of human plasma under magnetic stirring for 48 hours at $37^{\circ} \mathrm{C}$. Samples of $5 \mu \mathrm{L}$ were collected at $0.5,1,2,3,4,5,6,20,24,48$ and 72 hours and analyzed using high-performance liquid chromatography for content mass of ddMTX in the nanoemulsion.

\section{Cytotoxic activity assays}

Human erythroleukemia cells (K562) and human promyelocytic leukemia cells (HL60) were cultured in RPMI 1640 medium supplemented with streptomycin $50 \mu \mathrm{g} / \mathrm{mL}$, penicillin $50 \mathrm{IU} / \mathrm{mL}$, and $10 \%(\mathrm{v} / \mathrm{v})$ fetal calf serum (all from Invitrogen, Carlsbad, CA). Cells were maintained at $37^{\circ} \mathrm{C}$, $5 \% \mathrm{CO}_{2}$, and $100 \%$ relative humidity, and subcultivated 2-3 times a week, with $0.4 \%$ Trypan blue staining to assess cell growth and viability.

The starting inoculums of $5 \times 10^{5} \mathrm{~K} 562$ and HL60 cells $/ \mathrm{mL}$ were seeded in the exponential phase of growth into 96-well culture plates (Nunc TM, Roskilde, Denmark) with LDEddMTX (0.05-0.5 mM), methotrexate (2.5-37.5 mM), and lipid nanoemulsion, at the same volume as the lipid nanoemulsion with the associated drug, were added to the cells incubated. After 48 hours of incubation, the medium was removed and the number of living tumor cells was determined by the colorimetric MTT assay. ${ }^{31}$ Briefly, MTT solution was added to each well $(1.2 \mathrm{mg} / \mathrm{mL})$ and incubated for 4 hours. MTT was reduced by mitochondrial dehydrogenase in the viable cells to a purple formazan product, which was dissolved in $100 \mu \mathrm{L}$ dimethyl sulfoxide for measurement of absorbance at 570-655 $\mathrm{nm}$ in an enzyme-linked immunosorbent assay plate reader.

Cell viability of each well was expressed as the survival index. The $\mathrm{IC}_{50}$ was determined as the drug concentration required to achieve $50 \%$ cell growth inhibition.

\section{LDE-ddMTX uptake by neoplastic cells}

HL60 and K562 cell suspensions were seeded in $35 \mathrm{~mm}$ Petri dishes at $10^{5} \times$ cells $/ \mathrm{mL}$ and incubated at $37^{\circ} \mathrm{C}, 5 \% \mathrm{CO}_{2}$, and $100 \%$ relative humidity. After 24 hours of cell growth, the medium was replaced by fresh medium supplemented with $10 \%$ lipoprotein-deficient serum, and the cells were incubated for 24 hours in the same conditions. The medium was replaced by fresh medium supplemented with $10 \%$ fetal bovine serum, and increasing amounts of methotrexate and LDE-ddMTX were added at final drug concentrations ranging from 0.15 to $2.0 \mathrm{mM}$. After 4 hours of incubation at $37^{\circ} \mathrm{C}$, the cells were washed three times with cold phosphate-buffered saline, centrifuged at $1500 \mathrm{rpm}$ for 3 minutes, and then lysed in $1.0 \mathrm{~mL}$ of phosphate-buffered saline using a Branson Sonifier 450 sonicator for 10 seconds. Protein precipitation was performed with the addition of 500 $\mu \mathrm{L}$ 50:50 isopropyl alcohol to ethyl acetate and acetonitrile for ddMTX and methotrexate, respectively. The samples were mixed for one minute and centrifuged at $13000 \mathrm{rpm}$ for 10 minutes, and the supernatant was dried under nitrogen flow. Methanol and buffer of sodium acetate:acetonitrile (90:10) were used for ddMTX and methotrexate, respectively, as the mobile phase after extracting the drugs using Stracta cartridges (Phenomenex). The organic phase was concentrated and reconstituted in $0.2 \mathrm{~mL}$ of methanol and quantified by highperformance liquid chromatography. The Lowry protein quantification method was used to correct drug/mg of protein



\section{Maximum tolerated dose and $50 \%$ lethal dose of LDE-ddMTX}

Groups of 10 mice were intravenously injected via the retroorbital sinus, following a dose-escalation schedule based on three dose levels of methotrexate and LDE-ddMTX $(47,94$, and $180 \mathrm{mg} / \mathrm{kg})$. The studies were performed in two schedules, ie, a single-dose and a three-day multipledose schedule. Lipid nanoemulsion and saline control were administered. Animals were observed until day 7 and body weight measurements were performed every 2 days. The maximum tolerated dose (defined as the dose that resulted in approximately $15 \%$ loss in body weight and does not cause lethality). The lethal dose of $50 \%\left(\mathrm{LD}_{50}\right)$ was defined as the administered dose which caused death of $50 \%$ of the animals, calculated by interpolation of results (death percentage in the group/dose).

\section{Hematological toxicity}

Blood samples were collected 24 hours after injection of a single $180 \mathrm{mg} / \mathrm{kg}$ dose of LDE-ddMTX and methotrexate by retro-orbital sinus puncture, using heparinized Helmington microcapillary tubes. Hematology parameters included erythrocyte, leukocyte, leukocyte differential count, and platelets were performed using a hemocytometer (Optik 
Labor, Friedrichshafen, Germany). Briefly, blood was $1 / 1000$ diluted in saline for erythrocyte count, $1 / 100$ in Becker reagent for platelets, and $10 \mu \mathrm{L}$ was added to the hemocytometer. For leukocytes, blood was $1 / 100$ diluted in Turk reagent, and an aliquot of nondiluted blood was used on a glass slide for leukocyte differential count. Slides were stained using a Panoptic kit (Laborclin, Parana, Brazil). Erythrocytes and leukocytes were determined by counting the cells in the large squares, and platelets were counted in the central squares of the hemocytometer.

\section{Statistical analysis}

Cell uptake and $\mathrm{IC}_{50}$ data were expressed as the mean \pm standard error of the mean, and were analyzed by the nonparametric $t$-test. Kaplan-Meier analysis was used to assess survival in the different treatment groups. Maximum tolerated dose, $\mathrm{LD}_{50}$, and hematological profile values were also expressed as the mean \pm standard error of the mean, and were analyzed by analysis of variance followed by Bonferroni's test. In all analyses, differences of 0.05 or less were considered to be statistically significant.

\section{Results \\ Synthesis of LDE-ddMTX}

The methotrexate derivative, ddMTX, was obtained by esterification of the $\alpha$ - and $\gamma$-carbonyl groups of the glutamic acid residue in the presence of cesium carbonate and dodecyl bromide (Figure 1). The ddMTX structure was confirmed by ${ }^{1} \mathrm{H}$ and ${ }^{13} \mathrm{C} \mathrm{NMR}$, in which characteristic peaks corre-<smiles>CN(Cc1cnc2nc(N)nc(N)c2n1)c1ccc(C(=O)NC(CCC(=O)O[Na])C(=O)O[Na])cc1</smiles><smiles>CCCOC(=O)CCC(NC(=O)c1ccc(N(C)Cc2cnc3nc(N)nc(N)c3n2)cc1)C(=O)O[Al]C</smiles>

Figure I Esterification reaction of methotrexate in the presence of cesium carbonate. sponding to the dodecyl group were present. Esterification achieved a 98\% yield and a high purity rate, as confirmed by high-performance liquid chromatography analysis. Mass spectrometry showed a signal $791.48 \mathrm{~m} / \mathrm{z}$ corresponding to the molecular weight of the derivative. Those results were corroborated by the elemental analysis.

The esterification reaction markedly enhanced the methotrexate distribution coefficient, which was -1.4 before and 3.9 after the reaction. These data confirmed successful and optimized association with the lipid nanoemulsion, which attained a $98 \%$ association rate.

As analyzed by laser light scattering, the average particle size of the lipid nanoemulsion without ddMTX was approximately $40 \mathrm{~nm}$ and that of the lipid nanoemulsion with ddMTX was approximately $60 \mathrm{~nm}$. Transmission electron microscopy showed particles of quasispherical shape, with diameters in the same range as those measured by laser light scattering (Figure 2).
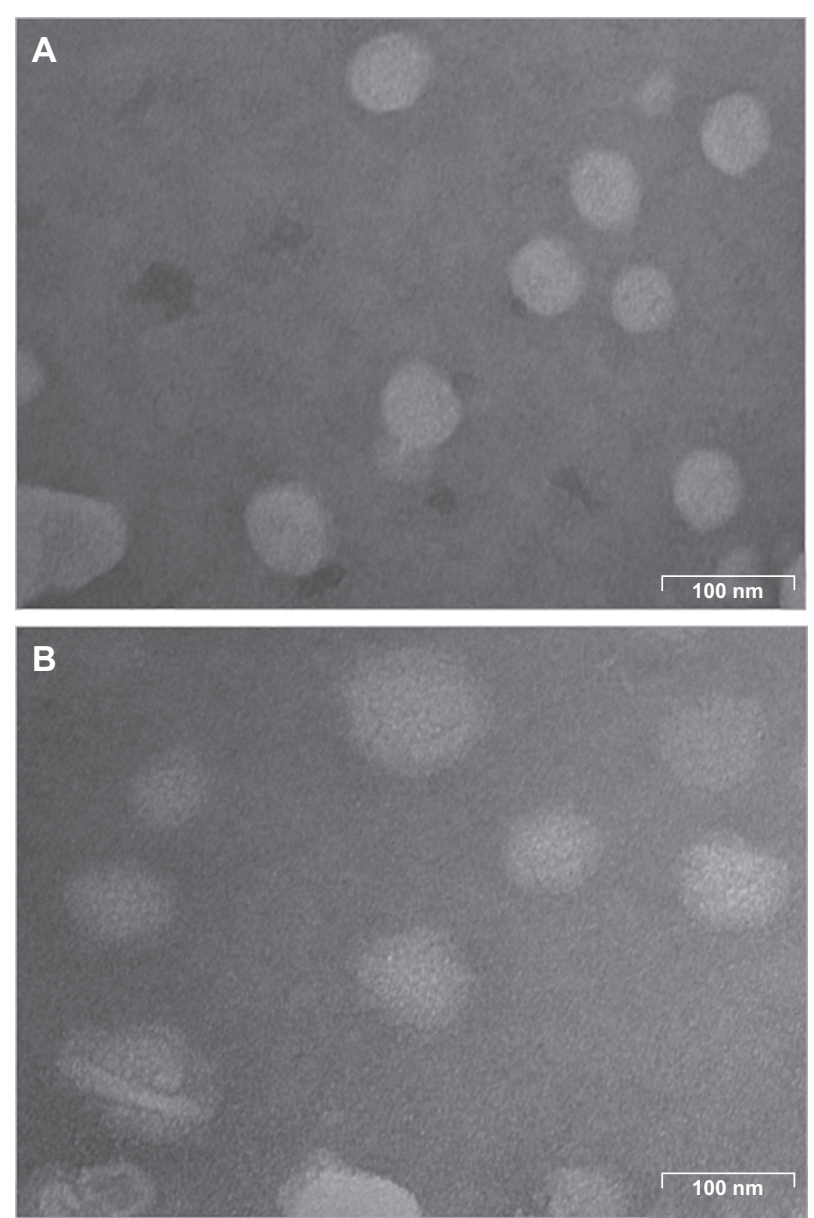

Figure 2 Transmission electron microscopy of (A) lipid nanoemulsion and (B) LDEddMTX.

Abbreviations: ddMTX, didodecyl methotrexate; LDE, lipid nanoemulsion. 


\section{Stability of LDE-ddMTX}

During the process of association of the drug with the lipid nanoemulsion, which comprised an ultrasonication step, there was no structural modification of the drug, a finding that was subsequently confirmed after 45 days of storage at $4^{\circ} \mathrm{C}$. On the other hand, the average size of LDE-ddMTX increased from $60 \mathrm{~nm}$ to $70 \mathrm{~nm}$. The rate of dissociation of ddMTX from the lipid nanoemulsion was $10 \% \pm 5 \%$, as observed at $4^{\circ} \mathrm{C}$ storage for 45 days. The ddMTX that dissociated from the lipid nanoemulsion was macroscopically observed by the appearance of a yellow powder of ddMTX at the bottom of the flask. The stability of the LDE-ddMTX association was analyzed over 48 hours of dialysis against human plasma. Free ddMTX was released from the dialysis bag at a slow rate of $28 \%$, and most of the dissociation occurred in the first 24 hours of the dialysis period (Figure 3).

\section{In vitro studies}

The cytotoxicity of LDE-ddMTX was markedly higher than that of methotrexate. For K562 cells, the cytotoxicity of the new formulation was approximately 10 -fold higher and for HL60 was 100-fold higher than for methotrexate (Figure 4, see Table 1). Incubation of HL60 and K562 with the lipid nanoemulsion alone did not inhibit cell growth. It is worthwhile to point out that the cytotoxicity of free unassociated
ddMTX was not tested because of its high lipophilicity that does not favor appropriate conditions for incubation with cells. For this purpose, it would be necessary to use organic solvents that would be toxic to the cells.

The $\mathrm{IC}_{50}$ for K562 cells incubated with LDE-ddMTX was $1.6 \mathrm{mM}$, whereas the $\mathrm{IC}_{50}$ for cells incubated with methotrexate was $18.2 \mathrm{mM}(P<0.0001)$. For the HL60 cells, the $\mathrm{IC}_{50}$ was $0.2 \mathrm{mM}$ for incubation with LDE-ddMTX and $26 \mathrm{mM}$ for incubation with methotrexate $(P=0.0002)$.

Figure 5 shows the uptake of LDE-ddMTX and methotrexate by K562 and HL60 cells 4 hours after incubation with increasing amounts of both preparations. The uptake amount refers to the nonmetabolized methotrexate and ddMTX found within the cells. It is notable that the uptake of LDE-ddMTX by K562 cells was 90-fold higher than that of methotrexate $(P<0.0001)$ while the uptake by HL60 was 75 -fold higher $(P<0.0001)$.

\section{In vivo toxicity}

The toxicity of both LDE-ddMTX and methotrexate to mice was tested in two escalating dose schedules, namely singledose and multiple-dose schedules. Using the single-dose schedule, the tolerability of methotrexate was greater than that of LDE-ddMTX, as evaluated by smaller weight loss and greater survival, despite the hematological toxicity of

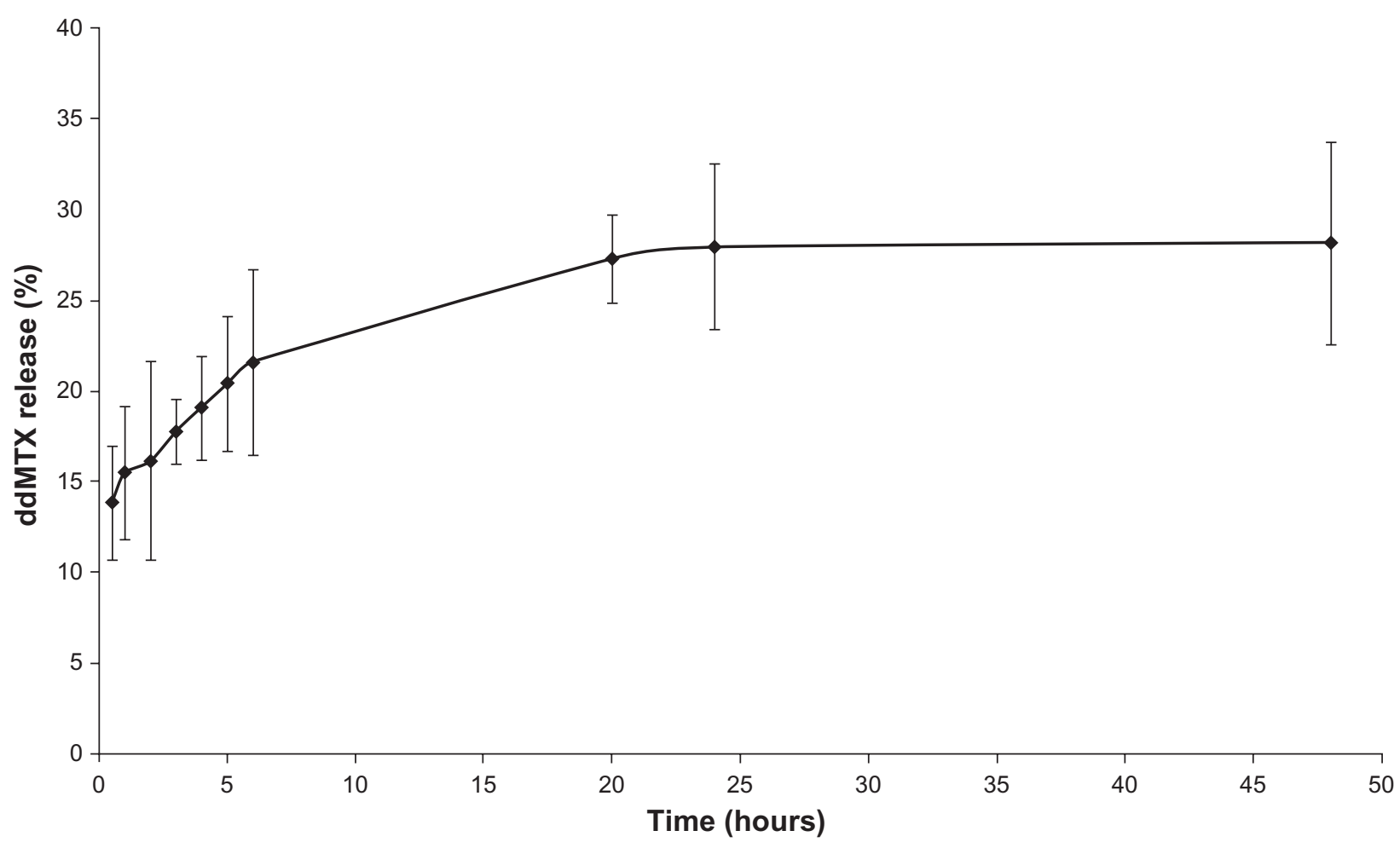

Figure 3 In vitro release profile of ddMTX from LDE in dialysis against human plasma at $37^{\circ} \mathrm{C}$ (mean \pm standard deviation, $\mathrm{n}=5$ ). Abbreviations: ddMTX, didodecyl methotrexate; LDE, lipid nanoemulsion. 

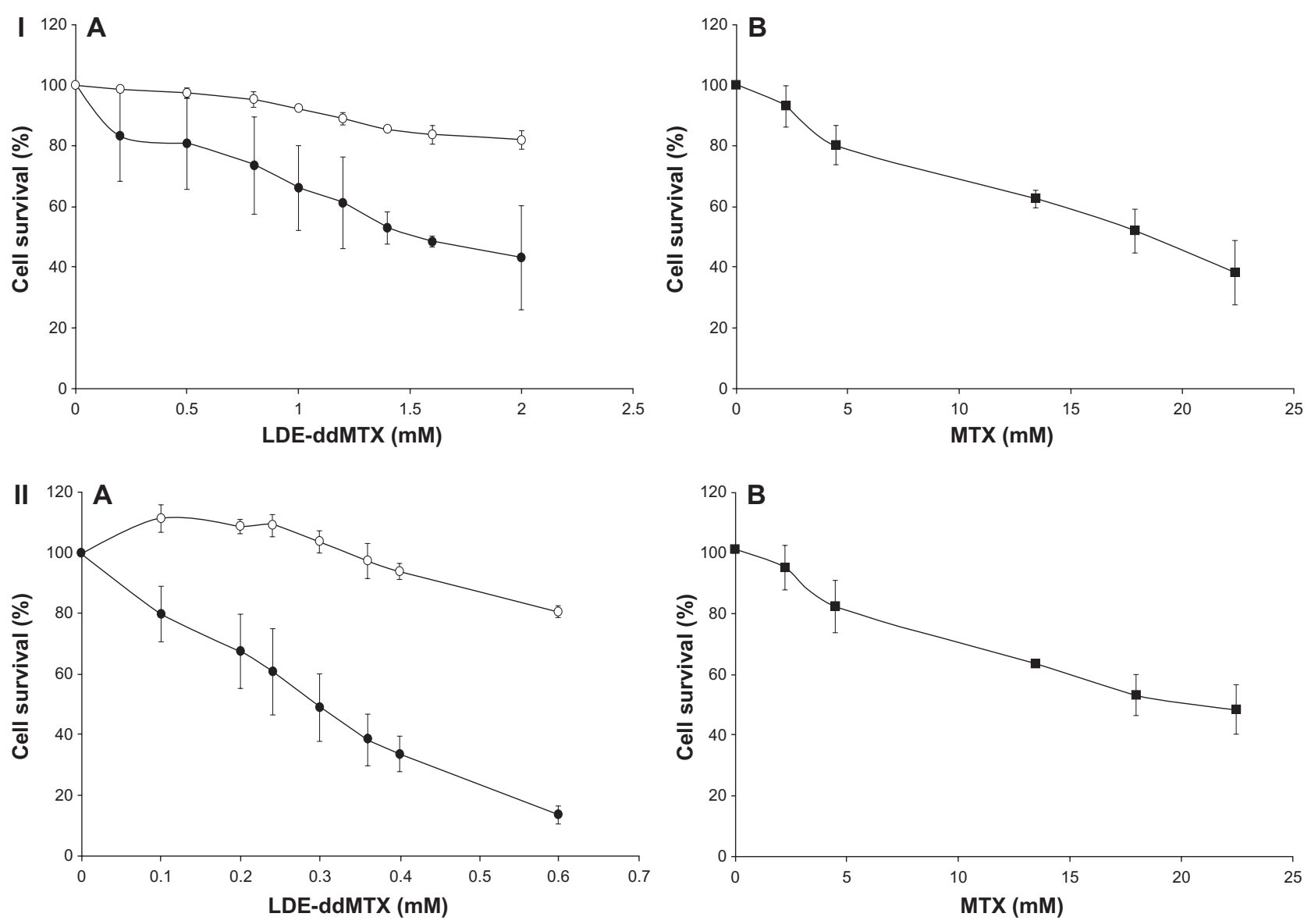

Figure 4 Cytotoxicity of (A) LDE (O), LDE-ddMTX $(\bullet)$, and methotrexate ( $\mathbf{\square})$ in (B) 562 (I) and HL60 (II) cell lines. The cells were incubated with the formulations (final concentration range $0.1-2.0 \mathrm{mM}$ ) for 4 hours at $37^{\circ} \mathrm{C}$, and survival was quantified by enzyme-linked immunosorbent assay. Results are presented the mean \pm standard error of the mean of three experiments.

Abbreviations: ddMTX, didodecyl methotrexate; LDE, lipid nanoemulsion.

LDE-ddMTX being lesser than that elicited by methotrexate (Figure 6). In the multiple-dose scheme, with both LDEddMTX and methotrexate treatments, all the animals died by the end of 7 days of observation. As shown in Table 2, both the MTD and the $\mathrm{LD}_{50}$ were higher for methotrexate than for LDE-ddMTX.

\section{Discussion}

The major achievement in this study was the manufacture of a formulation for methotrexate endowed with an ability to concentrate the drug into the cell at much greater rates than those of commercial methotrexate.

The excellent approximately $100 \%$ yield of the esterification reaction and the excellent approximately $100 \%$ association of ddMTX with the lipid nanoemulsion support the assumption that conditions for the manufacture of the LDEddMTX were near optimal. Esterification is a powerful strategy used in medicinal chemistry to improve drug features, such as passive transport, lipophilicity, and reduced toxicity.
Esterification of both the $\alpha$ - and $\gamma$-carbonyl groups used here was a practical alternative to regioselective esterification of only the $\gamma$-carbonyl group, which is often a low-yield reaction. The choice of dodecyl group to attach to methotrexate was based on a study by Rosowsky et $\mathrm{al}^{30}$ reporting that esters containing 10-12 carbon chains are more suited to maintain drug activity than long-chain methotrexate esters. The latter are less prone to bind to dihydrofolate reductase, which leads to decreased cytotoxicity. The higher distribution coefficient ( $n$-octanol/water) showed by

Table I $I_{50}$ values of methotrexate, ranging from 2.25 to $22.5 \mathrm{mM}$ and of LDE-dMTX, ranging from 0.1 to $2 \mathrm{mM}$ in $\mathrm{K} 562$ and HL60 cell lines. Cells were incubated for 48 hours at $37^{\circ} \mathrm{C}$

\begin{tabular}{lll}
\hline Formulations & $\mathrm{IC}_{\mathbf{5 0}}(\mathbf{m M})$ & $\mathbf{H L 6 0}$ \\
\cline { 2 - 3 } & $\mathbf{K 5 6 2}$ & 0.2 \\
\hline LDE-ddMTX & 1.6 & 26 \\
MTX & 18.2 & .
\end{tabular}

Abbreviations: ddMTX, didodecyl methotrexate; MTX, methotrexate; LDE, lipid nanoemulsion; $\mathrm{IC}_{50}, 50 \%$ inhibitory concentration. 

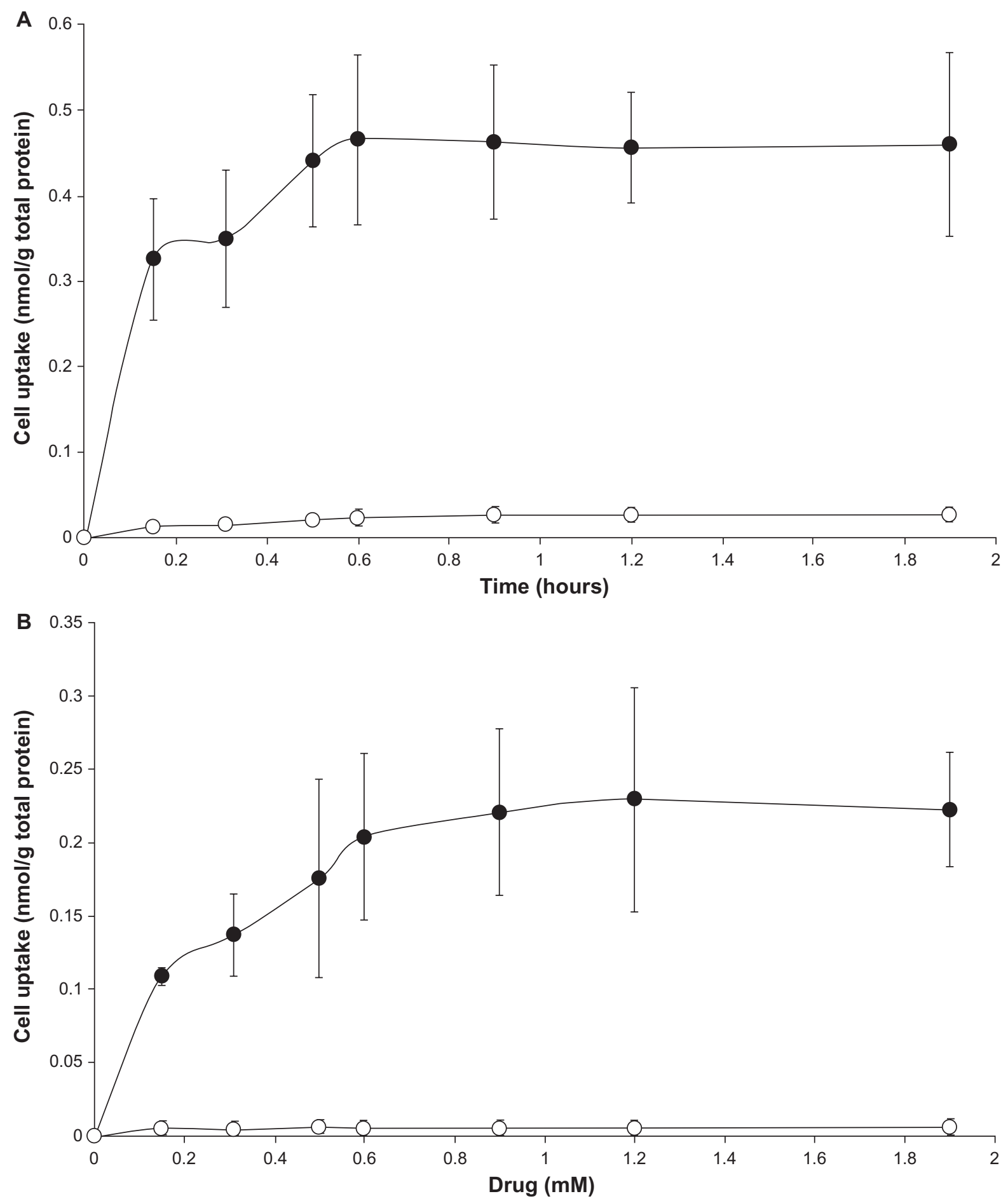

Figure 5 Uptake of LDE-ddMTX $(\bullet)$ and methotrexate (O) 4 hours by (A) K562 and (B) HL60 cell lines. Cells were incubated with the formulations (final concentration range $0.15-2.0 \mathrm{mM}$ ) for 4 hours at $37^{\circ} \mathrm{C}$, lysed, and the drugs were then quantified by high-performance liquid chromatography. Results are presented the mean \pm standard error of the mean of three experiments.

Abbreviations: ddMTX, didodecyl methotrexate; LDE, lipid nanoemulsion.

ddMTX compared with methotrexate, ie, 3.9 and -1.4 , respectively, was key to achieving the high entrapment efficiency obtained here.

Thus, both the esterification reaction and the procedure for associating the drug with the lipid nanoemulsion involve methods that are easy to perform, do not require expensive reagents, and can be easily adapted to large-scale production conditions. Ultimately, the particles of average size $60 \mathrm{~nm}$ resemble previously obtained preparations of lipid nanoemulsion-loaded paclitaxel, carmustine, or etoposide 

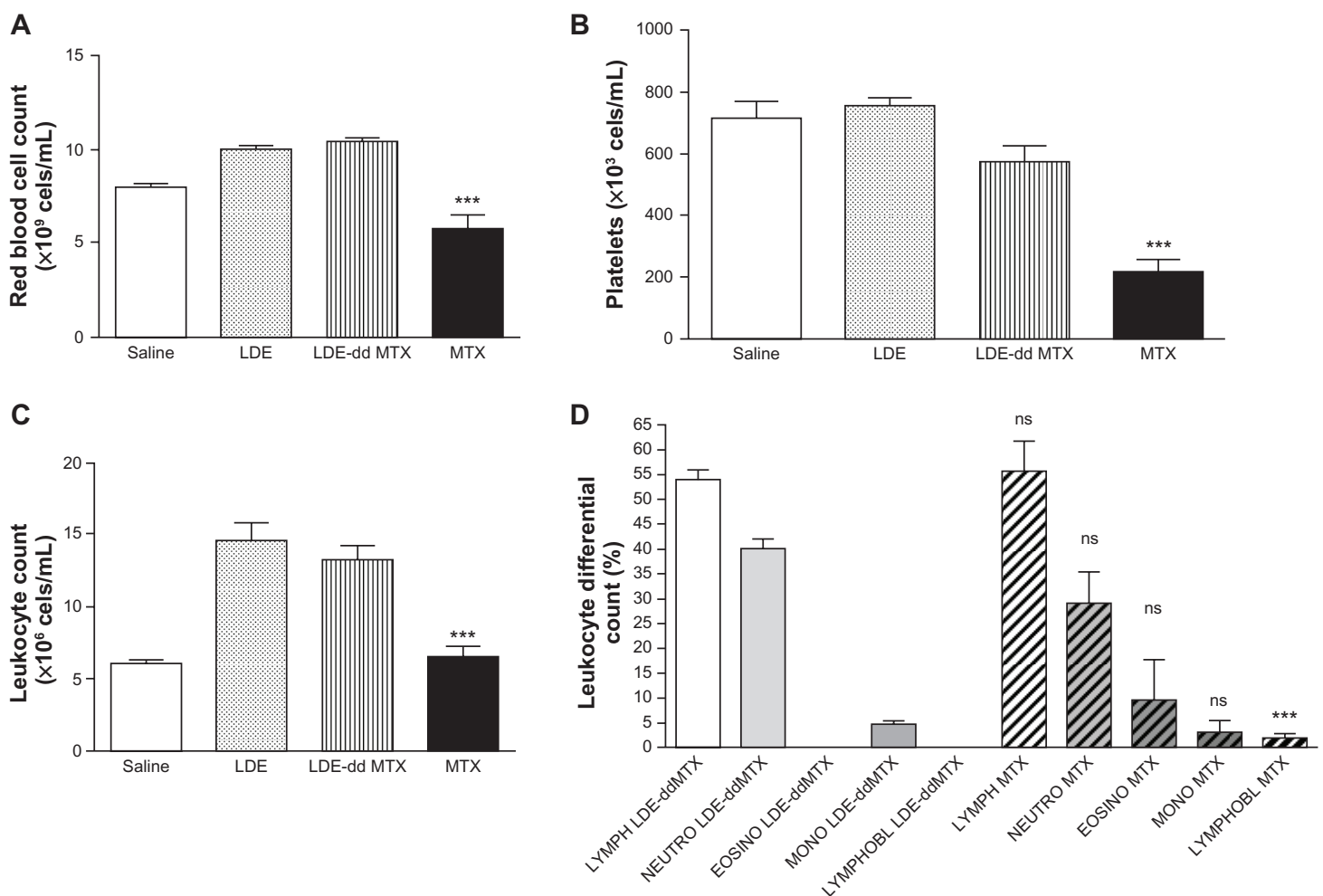

Figure 6 (A) Red cell count, (B) platelet count, (C) leukocyte count, and (D) leukocyte differential count in mice after 24 hours of intravenous LDE-ddMTX or methotrexate (both at $180 \mathrm{mg} / \mathrm{kg}$ dose) administration and after intravenous LDE without methotrexate.

Notes: ns indicates $P>0.05$; *** indicates $P<0.001$.

Abbreviations: ddMTX, didodecyl methotrexate; LDE, lipid nanoemulsion; LYMPH, lymphocytes; NEUTRO, neutrophyls; EOSINO, eosinophyls; MONO, monocytes; LYMPHOBL, lymphoblast.

derivatives. These previously described formulations showed the ability to produce a several-fold reduction in the toxicity of the associated chemotherapeutic agents, whereas the pharmacological action was preserved or even improved. ${ }^{21-23}$

A precondition for drug targeting is the stability of the drug-carrier in the circulation until final uptake by the targeted tissue. In the dialysis experiments, the fact that only a small fraction of the ddMTX associated with the lipid nanoemulsion was released from the bags over 48 hours supports the stability of the complex. A potential limitation of this experimental setting is that the interactions between plasma proteins and lipoproteins are more restricted, because

Table 2 Maximum tolerated dose and $50 \%$ lethal dose values of methotrexate and LDE-ddMTX intravenously administered as a single dose in $B A L B / c$ mice

\begin{tabular}{lll}
\hline Formulations & \multicolumn{2}{l}{ Single dose } \\
\cline { 2 - 3 } & MTD & LD $_{50}$ \\
\hline LDE-ddMTX & $47 \mathrm{mg} / \mathrm{kg}$ & $115 \mathrm{mg} / \mathrm{kg}$ \\
MTX & $94 \mathrm{mg} / \mathrm{kg}$ & $470 \mathrm{mg} / \mathrm{kg}$ \\
\hline
\end{tabular}

Abbreviations: ddMTX, didodecyl methotrexate; MTX, methotrexate; LDE, lipid nanoemulsion; $\mathrm{LD}_{50}, 50 \%$ lethal dose; MTD, maximum tolerated dose.
LDE-ddMTX particles are in a solution inside the dialysis bag whereas the plasma proteins are outside. Passage of proteins through the membrane is difficult due to their size, so interactions occur mainly at the membrane pores. ddMTX release from the lipid nanoemulsion could also be evaluated by mixing LDE-ddMTX with plasma inside the dialysis bag, but the drug eventually released from the lipid nanoemulsion could bind to plasma proteins or lipoproteins and remain in the bag, which would prevent dissociation from the lipid nanoemulsion.

LDE-ddMTX was mostly stable for at least 45 days. This was indicated by both the constant particle size and preservation of the ddMTX chemical structure during the observation period. As already mentioned in respect to drug entrapment by the lipid nanoemulsion, the increase in the distribution coefficient also contributes to the stability of the complex. Coalescence is critical for the stability of emulsions and other particulate systems. ${ }^{33}$ The lipid nanoemulsion is prepared with phosphatidylcholine, a positively charged phospholipid that produces more stable systems than negatively charged phospholipids. ${ }^{34}$

The uptake of methotrexate by cells occurs via folate receptors. Methotrexate is a substrate for polyglutamylation 
performed by folypolyglutamyl synthase that enhances cell retention of the drug. The enzyme activity varies among tumor cell lines, and it has been suggested that defective polyglutamation may partially account for tumor resistance to methotrexate. ${ }^{1}$ Therefore, it is remarkable that the cellular uptake of LDE-ddMTX was 75-fold higher than of methotrexate in HL60 cells and 90-fold higher in K562 cells. This finding can be ascribed to either the receptor-mediated endocytic pathway being furnished by the lipid nanoemulsion drug-carrier or to the lipophilic features of ddMTX. The biological activity of lipophilic derivatives of methotrexate can be either the result of a direct effect on cell enzymes, or being mediated by intracellular release of free drug, that will ultimately be responsible for the activity. ${ }^{35}$

The 75-fold greater uptake of LDE-ddMTX than methotrexate by HL60 cells was matched by 100 -fold greater cytotoxicity, whereas the 90 -fold greater uptake by K562 cells was linked with 10 -fold greater cytotoxicity to these cells. Our results suggest that uptake of methotrexate is an important limitation for cytotoxicity, and when cell internalization of the drug increases, the pharmacological action of the compound can be optimized. However, it is noteworthy that the greatest uptake did not correspond to the greatest cytotoxicity, because the cytotoxicity of K562 was not higher than for HL60. The mechanism of action of methotrexate involves inhibition of tetrahydrofolate synthesis through its bonding to dihydrofolate reductase, interfering with DNA synthesis and repair. The fact that there was no cytotoxicity when the lipid nanoemulsion was incubated with the two cell lines without methotrexate and demonstrates that this vehicle has no toxicity.

In the animal toxicity experiments, the marked differences created by the association of ddMTX and the lipid nanoemulsion were reflected in the fact that escalating doses resulted in lower survival rates for LDE-ddMTX compared with methotrexate at all dose levels. It is possible that the increased toxicity of LDE-ddMTX to animals was consequent to the marked increase in cell uptake and in vitro cytotoxicity. It is interesting that the hematological toxicity was lower for LDE-ddMTX, which suggests an as yet undetermined myeloprotective mechanism conferred by the lipid nanoemulsion.

The 10-90-fold greater cytotoxicity of LDE-ddMTX, which resulted in a four-fold increase in $\mathrm{LD}_{50}$, as estimated by animal survival, and a two-fold increase in the maximum tolerated dose, suggests that LDE-ddMTX can be used in smaller doses, and would still have superior pharmacological activity with low toxicity.
As a limitation of this study, it can be mentioned that a comparison between methotrexate and ddMTX both associated with the lipid nanoemulsion could not be made because methotrexate associates poorly with this nanoemulsion system.

The lipid nanoemulsion also has the ability to concentrate in atherosclerotic lesions, as shown in cholesterol-fed rabbits. ${ }^{36}$ In a subsequent as yet unpublished study, we observed that treatment of atherosclerotic rabbits with LDE-ddMTX resulted in marked regression of the lesions. This finding widens the potential therapeutic applications of LDE-ddMTX.

\section{Conclusion}

In conclusion, comparing LDE-ddMTX with other methotrexate delivery systems described in the literature, such as gelatin/methotrexate conjugates, ${ }^{37}$ polymers, ${ }^{7,8}$ liposomes, ${ }^{4,5}$ dendrimers, ${ }^{6}$ solid lipid nanoparticles, ${ }^{11,12}$ and chylomicronmimicking carrier emulsions, ${ }^{10}$ this novel formulation for intravenous use, in which the association of ddMTX with the vehicle is virtually complete and stable, showed equivalent or superior cytotoxicity. These findings warrant further preclinical investigation.

\section{Acknowledgments}

This study was supported by a State of Sao Paulo Research Foundation grant. Professor Maranhão has a research award from the National Council for Scientific and Technological Development. The authors are indebted to Sylvia M Carneiro for her help with the transmission electron microscopy experiments.

\section{Disclosure}

The authors report no conflicts of interest in this work.

\section{References}

1. Estlin EJ. Continuing therapy for childhood acute lymphoblastic leukaemia: clinical and cellular pharmacology of methotrexate, 6-mercaptopurine and 6-thioguanine. Cancer Treat Rev. 2001;27:351-363.

2. Huennekens FM. The methotrexate story: a paradigm for development of cancer chemotherapeutic agents. Adv Enzyme Regul. 1994;34:397-419.

3. Chabner BA, Ryan DP, Paz-Ares L, Garcia-Carbonero R, Calabresi P. Antineoplastic agents. In: Hardman JG, Limbird LE, Gilman A, editors. Goodman and Gilman's The Pharmacological Basis of Therapeutics. 10th ed. New York, NY: McGraw-Hill; 2001.

4. Kaasgaard T, Adresen TL, Jensen SS, Holte HO, Jensen LT, Jorgensen K. Liposomes containing alkylated methotrexate analogues for phospholipase $\mathrm{A}_{2}$ mediated tumor targeted drug delivery. Chem Phys Lipids. 2009;157:94-103.

5. Doddoli C, Chez O, Barlési F, et al. In vitro and in vivo methotrexate disposition in alveolar macrophages: Comparison of pharmacokinetic parameters of two formulations. Int J Pharm. 2005;297:180-189. 
6. Gurdag S, Khandare J, Stapels S, Metherly LH, Kannan RM. Activity of dendrimer-methotrexate conjugates on methotrexate-sensitive and -resistant cell lines. Bioconjug Chem. 2006;17:275-283.

7. LiY, Kwon GS. Micelle-like structures of poly(ethylene oxide)-blockpoly(2-hydroxyethyl aspartamide)-methotrexate conjugates. Colloids and Surfaces B: Biointerfaces. 1999;16:217-226.

8. Seo DH, Jeong YI, Kim DG, Jang MJ, Jang MK, Nah JW. Methotrexateincorporated polymeric nanoparticles of methoxypoly(ethyleneglycol)grafted chitosan. Colloids Surf B Biointerfaces. 2009;69:157-163.

9. Bai KB, Láng O, Orbán E, et al. Design, synthesis, and in vitro activity of novel drug delivery systems containing tuftsin derivatives and methotrexate. Bioconjug Chem. 2008;19:2260-2269.

10. Paliwal R, Paliwal SR, Mishra N, Mehta A, Vyas SP. Engineered chylomicron mimicking carrier emulsion for lymph targeted oral delivery of methotrexate. Int J Pharm. 2009;380:181-188.

11. Paliwal R, Rai S, Vaidya B, et al. Effect of lipid core material on characteristics of solid lipid nanoparticles designed for oral lymphatic delivery. Nanomedicine. 2009;5:184-191.

12. Ruckmani K, Sivakumar M, Ganeshkumar PA. Methotrexate loaded solid lipid nanoparticles (SLN) for effective treatment of carcinoma. J Nanosci Nanotechnol. 2006;6:2991-2995.

13. Ho YK, Smith RG, Brown MS, Goldstein JL. Low-density lipoprotein (LDL) receptor activity in human acute myelogenous leukemia cells Blood. 1978;52:1099-1114.

14. Masquelier M, Vitols S, Peterson C. Low-density lipoprotein as a carrier of antitumoral drugs: in vivo of drug-human low-density lipoproteins complexes in mice. Cancer Res. 1986;46:3842-3847.

15. Masquelier M, Vitols S, Palsson M, Mars U, Larsson BS, Peterson CO Low density lipoprotein as a carrier of cytostatics in cancer chemotherapy: study of stability of drug-carrier complexes in blood. J Drug Target. 2000;8:155-164.

16. Lundberg B. Preparation of drug-low density lipoprotein complexes for delivery of antitumoral drugs via the low density lipoprotein pathway. Cancer Res. 1987;47:4105-4108.

17. Vitols S, Angelin B, Ericsson SG, et al. Uptake of low density lipoproteins by human leukemic cells in vivo: relation to plasma lipoprotein levels and possible relevance for selective chemotherapy. Proc Natl Acad Sci U S A. 1990;87:2598-2602.

18. Maranhão RC, Garicochea B, Silva EL, Llacer PD, Pileggi FJC, Chamone DAF. Increased plasma removal of microemulsions resembling the lipid phase of low-density lipoproteins (LDL) in patients with acute myeloid leukemia: a possible new strategy for the treatment of the disease. Braz J Med Biol Res. 1992;25:1003-1007.

19. Maranhão RC, Garicochea B, Silva EL, et al. Plasma kinetics and biodistribution of a lipid emulsion resembling low-density lipoprotein in patients with acute leukemia. Cancer Res. 1994;54: 4660-4666.

20. Maranhão RC, César TB, Pedroso-Mariani SR, Hirata MH, Mesquita CH. Metabolic behavior in rats of a non-protein microemulsion resembling low density lipoprotein. Lipids. 1993;28:691-696.

21. Hungria VTM, Latrilha MC, Rodrigues DG, Bydlowsky SP, Chiattone CS, Maranhao RC. Metabolism of a cholesterol-rich microemulsion (LDE) in patients with multiple myeloma and preliminary clinical study of LDE as drug vehicle for the treatment of the disease. Cancer Chemother Pharmacol. 2004;53:51-60.
22. Rodrigues DG, Maria DA, Fernandes DC, et al. Improvement of paclitaxel therapeutic index by derivatization and association to a cholesterol-rich microemulsion: in vitro and in vivo studies. Cancer Chemother Pharmacol. 2005;55:565-576.

23. Valduga CJ, Fernandes DC, Lo Prete AC, Azevedo CHM, Rodrigues DG, Maranhao RC. Use of a cholesterol-rich microemulsion that binds to low-density lipoprotein receptors as vehicle for etoposide. $J$ Pharm Pharmacol. 2003;55:1615-1622.

24. Lo Prete AC, Maria DA, Rodrigues DG, Valduga CJ, Ibañez OC, Maranhão RC. Evaluation in melanoma-bearing mice of an etoposide derivative associated to a cholesterol-rich nano-emulsion. $J$ Pharm Pharmacol. 2006;58:801-808.

25. Ades A, Carvalho, JP, Graziani, SR, et al. Uptake of a cholesterolrich emulsion by neoplastic ovarian tissues. Gynecol Oncol. 2001;81:84-87.

26. Graziani SR, Igreja FAF, Hegg R, et al. Uptake of a cholesterol-rich emulsion by breast cancer. Gynecol Oncol. 2002;85:493-497.

27. Azevedo CH, Carvalho JP, Valduga CJ, Maranhão RC. Plasma kinetics and uptake by the tumor of a cholesterol-rich microemulsion (LDE) associated to etoposide oleate in patients with ovarian carcinoma. Gynecol Oncol. 2005;97:178-182.

28. Dias ML,Carvalho JP, Rodrigues DG, Graziani SR, Maranhão RC. Pharmacokinetics and tumor uptake of a derivatized form of paclitaxel associated to a cholesterol-rich nanoemulsion (LDE) in patients with gynecologic cancers. Cancer Chemother Pharmacol. 2007;59:105-111.

29. Pinheiro KV, Hungria VT, Ficker ES, Valduga CJ, Mesquita CH, Maranhao RC. Plasma kinetics of a cholesterol-rich microemulsion (LDE) in patients with Hodgkin's lymphoma and a preliminary study on the toxicity of etoposide associated with LDE. Cancer Chemother Pharmacol. 2006;57:624-630.

30. Rosowsky A, Forsch RA, Yu CS, Lazarus H, Beardsley GP. Methotrexate analogues. 21. Divergent influence of alkyl chain on the dihydrofolate reductase affinity and cytotoxicity of methotrexate monoesters. $J$ Med Chem. 1984;27:605-609.

31. Mosmann T. Rapid colorimetric assay for cellular growth and survival: application to proliferation and cytotoxicity assay. J Immunol Methods. 1983;65:55-63.

32. Lowry OH, Rosebrough NJ, Farr AL, Randall R. Protein measurement with the Folin phenol reagent. J Biol Chem. 1951;193:265-275.

33. Saito H, Kawagishi A, Tanaka M, et al. Coalescence of lipid emulsions in floating and freeze-thawing processes: examination of the coalescence transition state theory. J Colloid Interface Sci. 1999;219:129-134.

34. Kabalnov A, Tarara T, Arlauskas R, Werrs J. Phospholipids as emulsion stabilizers. 2. Phase behavior versus emulsion stability. J Colloid Interface Sci. 1996;184:227-235.

35. Pignatello R, Spampinato G, Sorrenti V, et al. Lipophilic methotrexate conjugates with antitumor activity. Eur J Pharm Sci. 2000;10:237-245.

36. Maranhão RC, Tavares ER, Padoveze AF, Valduga CJ, Rodrigues DG, Pereira MD. Paclitaxel associated with cholesterol-rich nanoemulsions promotes atherosclerosis regression in the rabbit. Atherosclerosis. 2008;197:959-966.

37. Ofner CM 3rd, Pica K, Bowman BJ, Chen CS. Growth inhibition, drug load, and degradation studies of gelatin/methotrexate conjugates. Int $J$ Pharm. 2006;308:90-99.
International Journal of Nanomedicine

\section{Publish your work in this journal}

The International Journal of Nanomedicine is an international, peerreviewed journal focusing on the application of nanotechnology in diagnostics, therapeutics, and drug delivery systems throughou the biomedical field. This journal is indexed on PubMed Central, MedLine, CAS, SciSearch ${ }^{\circledR}$, Current Contents ${ }^{\circledR} /$ Clinical Medicine,

\section{Dovepress}

Journal Citation Reports/Science Edition, EMBase, Scopus and the Elsevier Bibliographic databases. The manuscript management system is completely online and includes a very quick and fair peer-review system, which is all easy to use. Visit http://www.dovepress.com/ testimonials.php to read real quotes from published authors. 